\title{
Article \\ Quality of Life of Patients after Kinesio Tape Applications Following Impacted Mandibular Third Molar Surgeries
}

\author{
Aleksandra Jaroń ${ }^{\dagger}$, Olga Preuss ${ }^{\dagger}$, Berenika Konkol and Grzegorz Trybek*(D) \\ Department of Oral Surgery, Pomeranian Medical University in Szczecin, Powstańców Wielkopolskich 72/18, \\ 70-111 Szczecin, Poland; jaronola@gmail.com or aleksandra.jaron@pum.edu.pl (A.J.); \\ olga.preuss@pum.edu.pl (O.P.); berenika68@gmail.com (B.K.) \\ * Correspondence: g.trybek@gmail.com \\ + These authors made equal contributions as first author.
}

check for updates

Citation: Jaroń, A.; Preuss, O.; Konkol, B.; Trybek, G. Quality of Life of Patients after Kinesio Tape Applications Following Impacted Mandibular Third Molar Surgeries. J. Clin. Med. 2021, 10, 2197. https:// doi.org/10.3390/jcm10102197

Academic Editor: Emmanuel Andrès

Received: 10 February 2021

Accepted: 17 May 2021

Published: 19 May 2021

Publisher's Note: MDPI stays neutral with regard to jurisdictional claims in published maps and institutional affiliations.

Copyright: (c) 2021 by the authors. Licensee MDPI, Basel, Switzerland. This article is an open access article distributed under the terms and conditions of the Creative Commons Attribution (CC BY) license (https:// creativecommons.org/licenses/by/ $4.0 /)$.

\begin{abstract}
Today, extraction of the impacted third molar is the most common procedure performed in oral surgery departments. One of the methods currently investigated-in terms reducing the severity of non-infectious complications and decreasing Quality of Life following third molar surgeries-is Kinesio Taping (KT). The aim of the study was to evaluate the impact of Kinesio Tape application on Quality of Life. A total of 100 asymptomatic patients with impacted third lower molar were included. The study participants were randomly divided into two groups: a study group with the application of KT $(n=50)$ and a control group (without KT) $(n=50)$. Removal of the impacted third lower molar was performed in each patient in a standardized fashion. For assessment of Quality of Life, the modified University of Washington Quality of Life Questionnaire (UW-QoL v4) was used. Patients with Kinesio Tape application scored higher in all domains. Statistically significant differences between the two groups were found in the following domains: "Activity", "Mood", "Health-related QoL during the past 7 days" and "Overall QoL during the past 7 days". There were no significant differences in significant problems and important issues between groups. Kinesio Taping has a significant impact on Quality of Life after impacted third molar removal. It should be considered as one of the noninvasive methods to reduce postoperative non-infectious complications.
\end{abstract}

Keywords: pain; wisdom tooth removal; complications; kinesiotaping; oral surgery; quality of life

\section{Introduction}

Extraction of the impacted third molar (ITM) is the most common procedures performed in oral surgery departments [1-4]. After the procedure, the sequelae of noninfectious postoperative complications often occur, and these include trismus, post-extraction pain and edema. Their occurrence is more frequent following extraction of the lower ITM [1-3]. Even though typically not health-endangering, their frequency constitutes a major therapeutic problem which may significantly reduce the patients' quality of life (QoL) after surgery [5].

QoL is defined as a patient's perception of the impact of their disease or treatment, or both, on their daily life and their physical, psychological, and emotional wellbeing [6]. The basic methods of QOL assessment are various questionnaires which occasionally include pain scales, e.g., VAS — Visual Analogue Scale [7-10]. There is a number of studies assessing QoL after the removal of ITM. The majority of cases indicate a reduction in QOL during the recovery period.

Currently, several pharmacological and non-pharmacological methods are available to help to avoid or minimize these complications, and they mostly include corticosteroids or NSAIDs (nonsteroidal anti-inflammatory drugs), cryotherapy and LLLT (low-level laser therapy) [11-14]. Recently, it has been demonstrated that Kinesio Taping (KT) reduces the severity of non-infectious complications following third molar surgery [15-17]. According to some studies, this method may decrease post-extraction pain and trismus as well as may 
reduce the size of facial edema. The KT method was invented by Kenzo Kase in Japan in 2003 [18], and it is based on the application of Kinesio Tapes-thin, waterproof, adhesive, elastic tapes. The use of KT leads to the activation of mechanoreceptors, thus increasing the excitability of muscles by the central nervous system-by causing pressure, stretching the skin, and improving blood and lymph circulation by pulling the subcutaneous tissue and skin from the muscles [19]. KT is a non-invasive, hypoallergenic method which has a 24-h therapeutic effect. To the best of our knowledge, reports on the application of KT after third molar surgery are few and there is no single study investigating their impact on QoL.

The aim of the study was to evaluate the potential impact of KT on QoL in patients after surgical extraction of the impacted lower third molar.

\section{Materials and Methods}

The study was approved by the Bioethical Committee (KB-0012/152/13-KB-0012/135/15). A total of 100 healthy, asymptomatic patients with at least one impacted third lower molar were included in the study. Impaction was evaluated on panoramic $\mathrm{x}$-rays and indications for extraction were orthodontic reasons or previous pericoronitis. All cases were unilateral. Exclusion criteria included: any general diseases, patients under 18 years of age, pregnancy, lactation and tobacco smoking. Study participants were randomly divided into two parallel groups: a study group with the application of KT $(n=50)$ and a control group (without KT) $(n=50)$. One hundred opaque and sequentially numbered envelopes were used for concealment of allocation to trial groups. Each envelope contained a group assignment for one patient, determined in advance by a random number table. Extraction was performed under local anaesthesia using the same, standardized procedure. The block anaesthesia was made with 2 ampoules of $2 \%$ lidocaine with noradrenaline 1:80,000. All patients were asymptomatic and did not receive preoperative therapy. The standard protocol included buccal access and bone removal with rotary instruments. After extraction, the wound was rinsed with a sterile solution of physiological saline, and after achieving local hemostasis, the sutures were made. Because the Quality of Life questionnaire is somewhat subjective, patients in both the study and control groups were treated with ketoprofen in a $100 \mathrm{mg}$ dose taken twice daily after surgery to give the assurance that they were under medical care.

K-Active Tape Classic (Nitto Denko Corporation, Japan, distribution: K-Active Europe $\mathrm{GmbH}$, Germany) was applied to patients from the study group immediately after surgery. The length of the tape was individually adapted to each patient. KT was applied using the lymphatic technique to a patient's face [15], extending from the supraclavicular region to line where the largest swelling was suspected (Figure 1). The $5 \mathrm{~cm}$ tape was divided into 3 parts. It was recommended to keep the tapes for the next 5 postoperative days. Sutures were removed 7 days after surgery.

For the assessment of QoL, the modified University of Washington Quality of Life Questionnaire (UW-QoL v4) was used (Tables 1-5). This head and neck cancer HealthRelated Quality of Life Questionnaire was adapted to patients after third molar surgery [20]. The modified University of Washington Quality of Life Questionnaire (UW-QoLv4) consisted of 12 domains and 4 questions. This questionnaire focuses on current patient health and QoL within the past 7 days (Tables 1-4) Its modification consisted of alteration in domains No. 8 and 13, in which the word "shoulder" was replaced with the word "face", and, in domains No. 11 and 12, the word "cancer" was replaced with the word "operation". These modifications resulted in better adaptation to oral surgery patients. Every patient was asked to fill in UW-QoL v4 before the procedure and in the 7th postoperative day. 


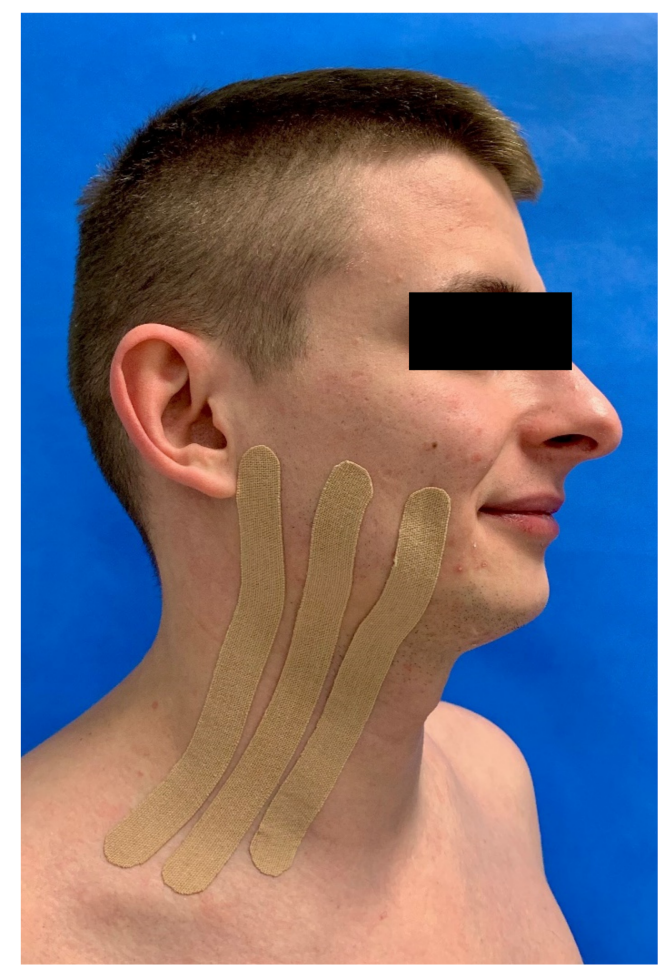

Figure 1. Kinesio Tape application.

Table 1. Questionaire's domains.

1. Pain

I have no pain. (100)

There is mild pain not needing medication. (75)

I have moderate pain-requires regular medication. (50)

I have severe pain controlled only by prescription medicine. (25)

I have severe pain, not controlled by medication. (0)

2. Appearance

There is no change in my appearance. (100)

The change in my appearance is minor. (75)

My appearance bothers me but I remain active. (50)

I feel significantly disfigured and limit my activities due to my appearance. (25)

I cannot be with people due to my appearance. (0)

3. Activity

I am as active as I have ever been. (100)

There are times when I can't keep up my old pace, but not often. (75)

I am often tired and have slowed down my activities although I still get out. (50)

I don't go out because I don't have the strength. (25)

I am usually in bed or chair and don't leave home. (0)

4. Recreation

There are no limitations to recreation at home or away from home. (100)

There are a few things I can't do but I still get out and enjoy life. (75)

There are many times when I wish I could get out more, but I'm not up to it. (50)

There are severe limitations to what I can do, mostly I stay at home and watch

TV. (25)

I can't do anything enjoyable. (0)

5. Swallowing

I can swallow as well as ever. (100)

I cannot swallow certain solid foods. (70)

I can only swallow liquid food. (30)

I cannot swallow because it "goes down the wrong way" and chokes me. (0) 
Table 1. Cont.

6. Chewing.

I can chew as well as ever. (100)

I can eat soft solids but cannot chew some foods. (50)

I cannot even chew soft solids. (0)

7. Speech.

My speech is the same as always. (100)

I have difficulty saying some words but I can be understood over the phone. (70)

Only my family and friends can understand me. (30).

I cannot be understood. (0)

8. Face

I have no problem with my face. (100)

My face is stiff but it has not affected my activity or strength. (70)

Pain or weakness of my face has caused me to change my work/hobbies. (30)

I cannot work or do my hobbies due to problems with my face. (0)

9. Taste

I can taste food normally. (100)

I can taste most foods normally. (70)

I can taste some foods. (30)

I cannot taste any foods. (0)

10. Saliva

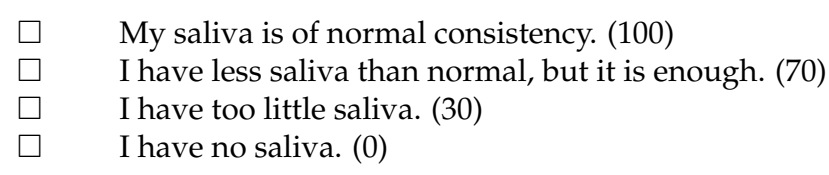

11. Mood

$\square \quad$ My mood is excellent and unaffected by the operation. (100)

My mood is generally good and only occasionally affected by the operation. (75)

I am neither in a good mood nor depressed about the operation. (50)

I am somewhat depressed about the operation. (25)

I am extremely depressed about the operation. (0)

12. Anxiety

$\square \quad$ I am not anxious about the operation. (100)

I am a little anxious about the operation. (70)

I am anxious about the operation. (30)

I am very anxious about the operation. (0)

Table 2. Important issues.

13. Which issues have been the most important to you during the past 7 days? Tick up to 3 boxes.

\begin{tabular}{ccc}
\hline$\square$ Pain & $\square$ Swallowing & $\square$ Taste \\
$\square$ Appearance & $\square$ Chewing & $\square$ Saliva \\
$\square$ Activity & $\square$ Speech & $\square$ Mood \\
$\square$ Recreation & $\square$ Shoulder & $\square$ Anxiety \\
\hline
\end{tabular}


Table 3. Questionnaire's global questions.

General Questions:

1. Compared to the month before you developed cancer, how would you rate your health-related quality of life? (Tick one box:)

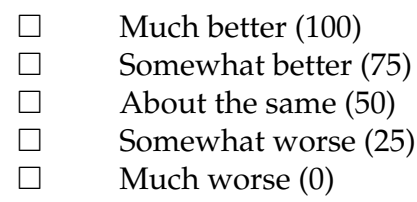

2. In general, would you say your health-related quality of life during the past 7 days has been: (Tick one box:)

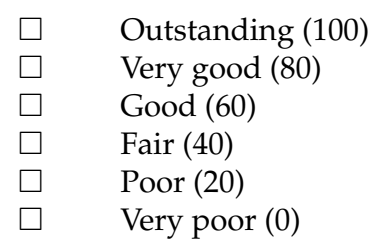

3. Overall quality of life includes not only physical and mental health, but also many other factors, such as family, friends, spirituality, or personal leisure activities that are important to your enjoyment of life. Considering everything in your life that contributes to your personal well-being, rate your overall quality of life during the past 7 days.

$\begin{array}{ll}\square & \text { Outstanding (100) } \\ \square & \text { Very good (80) } \\ \square & \text { Good (60) } \\ \square & \text { Fair (40) } \\ \square & \text { Poor (20) } \\ \square & \text { Very poor (0) }\end{array}$

Table 4. Significant problem-key for scoring [18].

\begin{tabular}{cc}
\hline Significant Problem & Scores \\
\hline Pain, appearance, activity, recreation, mood & 0, 25, 50 with important issue (question 13) \\
\hline Swallowing, speech, anxiety & 0,30 \\
\hline Shoulder, taste, saliva & 0, 30 with important issue (question 13) \\
\hline Chewing & 0 \\
\hline
\end{tabular}

Table 5. Study groups characteristic.

\begin{tabular}{|c|c|c|c|c|c|c|c|c|}
\hline \multirow[t]{3}{*}{$\begin{array}{c}\text { Baseline } \\
\text { Characteristic }\end{array}$} & \multicolumn{2}{|c|}{ Age (Years) } & \multicolumn{2}{|c|}{$\begin{array}{l}\text { Procedure Time } \\
\text { (Minutes) }\end{array}$} & \multicolumn{4}{|c|}{ Sex } \\
\hline & \multirow[b]{2}{*}{ Median } & \multirow[b]{2}{*}{ Range } & \multirow[b]{2}{*}{ Median } & \multirow[b]{2}{*}{ Range } & \multicolumn{2}{|c|}{ Female } & \multicolumn{2}{|c|}{ Male } \\
\hline & & & & & $\mathbf{n}$ & $\%$ & $\mathbf{n}$ & $\%$ \\
\hline Study group $(n=50)$ & 26.5 & $19-59$ & 21 & $10-60$ & 36 & 72 & 14 & 28 \\
\hline $\begin{array}{l}\text { Control group } \\
\quad(\mathrm{n}=50)\end{array}$ & 25 & $18-38$ & 24.5 & $6-60$ & 38 & 76 & 12 & 24 \\
\hline $\begin{array}{c}\text { Total } \\
(\mathrm{n}=100)\end{array}$ & 25.5 & $18-59$ & 23 & $6-60$ & 74 & 74 & 26 & 26 \\
\hline$p$-value ${ }^{1}$ & \multicolumn{2}{|c|}{0.221} & \multicolumn{2}{|c|}{0.801} & \multicolumn{4}{|c|}{$p$-value ${ }^{2} 0.82$} \\
\hline
\end{tabular}

${ }^{1}$ Mann-Whitney test ${ }^{2}$ Chi-square test.

Power was calculated using the method described by Shieh et al. and the R package "wmwpow" [21]. (Shieh, G., Jan, S.L., Randles, R.H. (2006). On power and sample size determinations for the Wilcoxon-Mann-Whitney test. Journal of Nonparametric Statistics, 
18(1), 33-43.) Shieh power was $80 \%$ assuming $5 \%$ alpha and an effect size (given as the probability that outcomes were different between the groups) of $66 \%$ (two-sided).

Statistical analysis was carried out using the statistical R package. The normality of the distribution of variables was assessed using the Shapiro-Wilk test. The Mann-Whitney test was implemented for comparative analysis of quantitative variables of the study groups in the absence of normality of their distribution. The qualitative variables between both groups were compared using the chi-square test. For the analysis of qualitative variables in the $2 \times 2$ tables, a chi-square test with Yates correction was employed. In the case where low values were expected in the tables $(<5)$, Fisher's exact test was used. In all calculations, a $p$-value of less than 0.05 was considered significant.

\section{Results}

\subsection{Group Characteristics}

The number of patients who took part in the study totalled 100. The study group consisted of 36 females and 14 males, while the control group consisted of 38 females and 12 males. The age of patients in the study group ranged from 19 to 59 years, while, in the control group, the range was between 18 and 38 years. The time of the procedure was similar in both groups $(p=0.801)$. The groups did not differ significantly in terms of age and sex $(p>0.05)$. Likewise, the time of the procedure measured in minutes did not show significant differences (Table 5). None of the patients in the study reported side effects after using KT.

\subsection{QOL Results}

We discovered significant differences between the two groups in the following domains: "Activity", "Mood", "Health-related QOL during the past 7 days" and "Overall QOL during the past 7 days". Patients with KT application scored higher in the above domains (Table 6). There was also a significant decrease in overall QOL during the seven postoperative days in patients of the control group (Table 7). Interestingly, we did not reveal significant differences between the study groups in terms of choosing important issues and significant problems. Patients of both groups indicated that the most important issue and problem during the seven postoperative days were pain sensations. The last question in the questionnaire concerned issues that were most important to the patient during the last 7 days (Figure 2). Every patient was asked to indicate up to three issues. Significant problems were evaluated using specific algorithms to calculate the score. They use information from domain scores and the question of the important issues (Table 6; Figure 3).

Table 6. The comparative analysis of QOL between the study groups during 7 postoperative days.

\begin{tabular}{|c|c|c|c|c|c|c|c|c|c|c|}
\hline Domain & Group & $\mathbf{n}$ & Mean & SD & Min & Q1 & Median & Q3 & Max & $p^{*}$ \\
\hline \multirow[b]{2}{*}{ Pain } & study & 50 & 53 & 27.03 & 0 & 25 & 50 & 75 & 100 & \multirow[b]{2}{*}{0.287} \\
\hline & control & 50 & 47.5 & 26.85 & 0 & 25 & 37.5 & 75 & 100 & \\
\hline \multirow{2}{*}{ Appearance } & study & 50 & 68.5 & 25.16 & 25 & 50 & 75 & 100 & 100 & \multirow{2}{*}{0.249} \\
\hline & control & 50 & 62 & 27.77 & 25 & 31.25 & 75 & 75 & 100 & \\
\hline \multirow{2}{*}{ Activity } & study & 50 & 81.5 & 21.91 & 0 & 75 & 75 & 100 & 100 & \multirow{2}{*}{0.017} \\
\hline & control & 50 & 68 & 29.47 & 0 & 50 & 75 & 100 & 100 & \\
\hline \multirow{2}{*}{ Recreation } & study & 50 & 78 & 23.5 & 25 & 75 & 75 & 100 & 100 & \multirow{2}{*}{0.346} \\
\hline & control & 50 & 70 & 31.94 & 0 & 50 & 75 & 100 & 100 & \\
\hline \multirow{2}{*}{ Swallowing } & study & 50 & 83 & 25.01 & 30 & 70 & 100 & 100 & 100 & \multirow{2}{*}{0.366} \\
\hline & control & 50 & 79.2 & 25.54 & 30 & 70 & 100 & 100 & 100 & \\
\hline
\end{tabular}


Table 6. Cont.

\begin{tabular}{|c|c|c|c|c|c|c|c|c|c|c|}
\hline Domain & Group & $\mathbf{n}$ & Mean & SD & Min & Q1 & Median & Q3 & Max & $p^{*}$ \\
\hline \multirow{2}{*}{ Chewing } & study & 50 & 59 & 29.78 & 0 & 50 & 50 & 100 & 100 & \multirow{2}{*}{0.351} \\
\hline & control & 50 & 54 & 26.42 & 0 & 50 & 50 & 50 & 100 & \\
\hline \multirow{2}{*}{ Speech } & study & 50 & 89.6 & 16.28 & 30 & 70 & 100 & 100 & 100 & \multirow{2}{*}{0.734} \\
\hline & control & 50 & 89.2 & 14.55 & 70 & 70 & 100 & 100 & 100 & \\
\hline \multirow{2}{*}{ Face } & study & 50 & 73.6 & 27.98 & 0 & 70 & 70 & 100 & 100 & \multirow{2}{*}{0.659} \\
\hline & control & 50 & 69.8 & 31.53 & 0 & 40 & 70 & 100 & 100 & \\
\hline \multirow{2}{*}{ Taste } & study & 50 & 91.4 & 15.65 & 30 & 77.5 & 100 & 100 & 100 & \multirow{2}{*}{0.154} \\
\hline & control & 50 & 82.2 & 27.65 & 0 & 70 & 100 & 100 & 100 & \\
\hline \multirow{2}{*}{ Saliva } & study & 50 & 95 & 13.59 & 30 & 100 & 100 & 100 & 100 & \multirow{2}{*}{0.625} \\
\hline & control & 50 & 94.6 & 11.64 & 70 & 100 & 100 & 100 & 100 & \\
\hline \multirow{2}{*}{ Mood } & study & 50 & 74 & 18.87 & 25 & 75 & 75 & 75 & 100 & \multirow{2}{*}{0.048} \\
\hline & control & 50 & 65 & 23.15 & 25 & 50 & 75 & 75 & 100 & \\
\hline \multirow{2}{*}{ Anxiety } & study & 50 & 81.2 & 21.06 & 30 & 70 & 70 & 100 & 100 & \multirow{2}{*}{0.863} \\
\hline & control & 50 & 80.6 & 20.94 & 30 & 70 & 70 & 100 & 100 & \\
\hline \multirow{2}{*}{ Physical function } & study & 50 & 81.08 & 15.39 & 30.83 & 73.33 & 82.92 & 91.67 & 100 & \multirow{2}{*}{0.24} \\
\hline & control & 50 & 76.87 & 16.84 & 42.5 & 63.75 & 78.33 & 87.5 & 100 & \\
\hline \multirow[b]{2}{*}{ Social-Emotional Function } & study & 50 & 73.46 & 18.24 & 25 & 64 & 79 & 89 & 100 & \multirow{2}{*}{0.188} \\
\hline & control & 50 & 67.18 & 22.63 & 11 & 49.25 & 70 & 87.75 & 100 & \\
\hline \multirow{2}{*}{$\begin{array}{l}\text { Health-related QoL compared } \\
\text { to time before surgery }\end{array}$} & study & 50 & 63 & 27.31 & 0 & 50 & 50 & 75 & 100 & \multirow{2}{*}{0.509} \\
\hline & control & 50 & 67 & 28.32 & 0 & 50 & 62.5 & 100 & 100 & \\
\hline \multirow{2}{*}{$\begin{array}{l}\text { Health-related QoL during the } \\
\text { past } 7 \text { days }\end{array}$} & study & 50 & 56 & 18.52 & 0 & 40 & 60 & 60 & 80 & \multirow{2}{*}{0.021} \\
\hline & control & 50 & 46.8 & 20.84 & 0 & 40 & 40 & 60 & 80 & \\
\hline \multirow{2}{*}{$\begin{array}{l}\text { Overall QoL during the past } \\
7 \text { days }\end{array}$} & study & 50 & 64.4 & 19.5 & 20 & 60 & 60 & 80 & 100 & \multirow{2}{*}{0.003} \\
\hline & control & 50 & 52.8 & 19.7 & 20 & 40 & 60 & 60 & 100 & \\
\hline
\end{tabular}

* Mann-Whitney test; $n$ —number of patients; SD—standard deviation; Min—minimum value; Max—maximum value; Q1—first quartile; Q3-third quartile; $p$-significance level.

Table 7. Changes in QoL between 7th postoperative day and pre-operative period.

\begin{tabular}{|c|c|c|c|c|c|c|c|c|c|c|}
\hline Domain & Group & $\mathrm{n}$ & Mean & SD & Min & Q1 & Median & Q3 & $\operatorname{Max}$ & $p^{*}$ \\
\hline \multirow[b]{2}{*}{ Pain } & study & 50 & 39.5 & 27.71 & 0 & 25 & 37.5 & 75 & 75 & \multirow{2}{*}{0.321} \\
\hline & control & 50 & 45 & 27.66 & 0 & 25 & 50 & 75 & 75 & \\
\hline \multirow{2}{*}{ Appearance } & study & 50 & 28 & 25.58 & -25 & 0 & 25 & 50 & 75 & \multirow{2}{*}{0.176} \\
\hline & control & 50 & 36 & 28.64 & 0 & 0 & 25 & 50 & 75 & \\
\hline \multirow{2}{*}{ Activity } & study & 50 & 13 & 24.35 & -50 & 0 & 0 & 25 & 100 & \multirow{2}{*}{0.045} \\
\hline & control & 50 & 25 & 29.01 & -25 & 0 & 25 & 50 & 100 & \\
\hline \multirow{2}{*}{ Recreation } & study & 50 & 16.5 & 26.54 & -25 & 0 & 0 & 25 & 75 & \multirow{2}{*}{0.544} \\
\hline & control & 50 & 22 & 32.2 & -25 & 0 & 0 & 50 & 100 & \\
\hline \multirow{2}{*}{ Swallowing } & study & 50 & 16.4 & 25.05 & 0 & 0 & 0 & 30 & 70 & \multirow[b]{2}{*}{0.363} \\
\hline & control & 50 & 20.2 & 25.67 & 0 & 0 & 0 & 30 & 70 & \\
\hline \multirow{2}{*}{ Chewing } & study & 50 & 35 & 30.72 & 0 & 0 & 50 & 50 & 100 & \multirow{2}{*}{0.112} \\
\hline & control & 50 & 44 & 27.92 & 0 & 50 & 50 & 50 & 100 & \\
\hline \multirow{2}{*}{ Speech } & study & 50 & 8.6 & 17.84 & -30 & 0 & 0 & 30 & 70 & \multirow{2}{*}{0.611} \\
\hline & control & 50 & 9.6 & 16.53 & -30 & 0 & 0 & 30 & 30 & \\
\hline
\end{tabular}


Table 7. Cont.

\begin{tabular}{|c|c|c|c|c|c|c|c|c|c|c|}
\hline Domain & Group & $\mathrm{n}$ & Mean & SD & Min & Q1 & Median & Q3 & Max & $p^{*}$ \\
\hline \multirow[b]{2}{*}{ Face } & study & 50 & 24.6 & 26.2 & 0 & 0 & 30 & 30 & 100 & \multirow{2}{*}{0.8} \\
\hline & control & 50 & 27.8 & 32.41 & -30 & 0 & 30 & 37.5 & 100 & \\
\hline \multirow{2}{*}{ Taste } & study & 50 & 6.2 & 12.6 & 0 & 0 & 0 & 0 & 40 & \multirow[b]{2}{*}{0.143} \\
\hline & control & 50 & 16 & 28.43 & -30 & 0 & 0 & 30 & 100 & \\
\hline \multirow[b]{2}{*}{ Saliva } & study & 50 & 4.4 & 11.1 & 0 & 0 & 0 & 0 & 40 & \multirow[b]{2}{*}{1} \\
\hline & control & 50 & 4.2 & 12.14 & -30 & 0 & 0 & 0 & 30 & \\
\hline \multirow{2}{*}{ Mood } & study & 50 & 10 & 19.56 & -25 & 0 & 0 & 25 & 50 & \multirow[b]{2}{*}{0.064} \\
\hline & control & 50 & 19.5 & 26.39 & -25 & 0 & 25 & 25 & 75 & \\
\hline \multirow{2}{*}{ Anxiety } & study & 50 & 13.4 & 22.73 & -30 & 0 & 0 & 30 & 70 & \multirow{2}{*}{0.882} \\
\hline & control & 50 & 13.2 & 24.94 & -70 & 0 & 0 & 30 & 70 & \\
\hline \multirow{2}{*}{ Physical function } & study & 50 & 16.43 & 14.09 & -5 & 4.17 & 16.67 & 23.12 & 53.33 & \multirow{2}{*}{0.138} \\
\hline & control & 50 & 21.67 & 16.44 & -5 & 9.37 & 19.58 & 35 & 57.5 & \\
\hline \multirow{2}{*}{ Social-Emotional Function } & study & 50 & 21.4 & 18.05 & 0 & 7 & 15,5 & 35.5 & 70 & \multirow{2}{*}{0.332} \\
\hline & control & 50 & 26.6 & 22.51 & -14 & 7 & 26.5 & 43.75 & 81 & \\
\hline \multirow{2}{*}{$\begin{array}{l}\text { Health-related QoL compared } \\
\text { to time before surgery }\end{array}$} & study & 50 & -2 & 30.66 & -50 & -25 & 0 & 0 & 75 & \multirow{2}{*}{0.137} \\
\hline & control & 50 & -12 & 37.88 & -100 & -50 & 0 & 0 & 100 & \\
\hline \multirow{2}{*}{$\begin{array}{l}\text { Health-related QoL during the } \\
\text { past } 7 \text { days }\end{array}$} & study & 50 & 15.6 & 22.6 & -20 & 0 & 20 & 20 & 100 & \multirow{2}{*}{0.116} \\
\hline & control & 50 & 22.4 & 27 & -40 & 5 & 20 & 40 & 80 & \\
\hline \multirow{2}{*}{$\begin{array}{c}\text { Overall QoL during the past } \\
7 \text { days }\end{array}$} & study & 50 & 10.8 & 22.57 & -40 & 0 & 10 & 20 & 60 & \multirow{2}{*}{0.028} \\
\hline & control & 50 & 20.8 & 21.37 & -20 & 0 & 20 & 40 & 60 & \\
\hline
\end{tabular}

* Mann-Whitney test; $n$ —number of patients; SD—standard deviation; Min—minimum value; Max—maximum value; Q1—first quartile; Q3-third quartile; $p$-significance level.

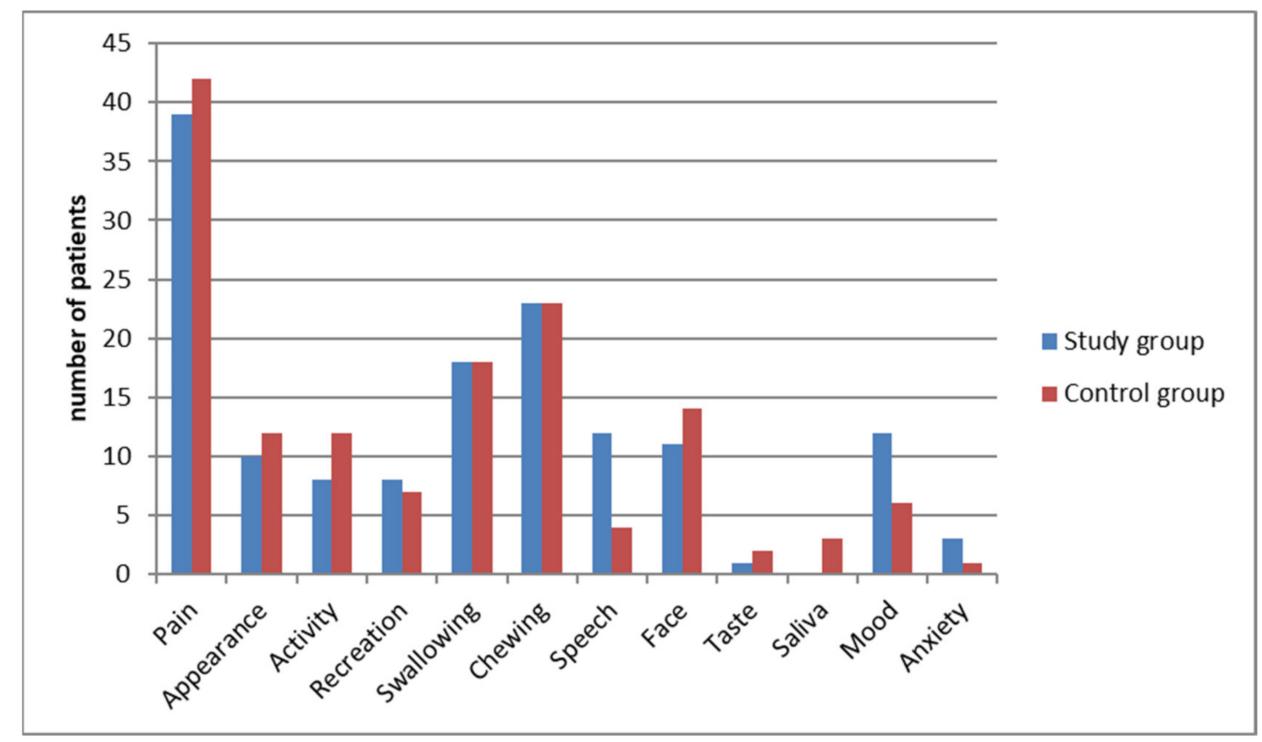

Figure 2. Important issues for patients during recovery after removal of ITM. 


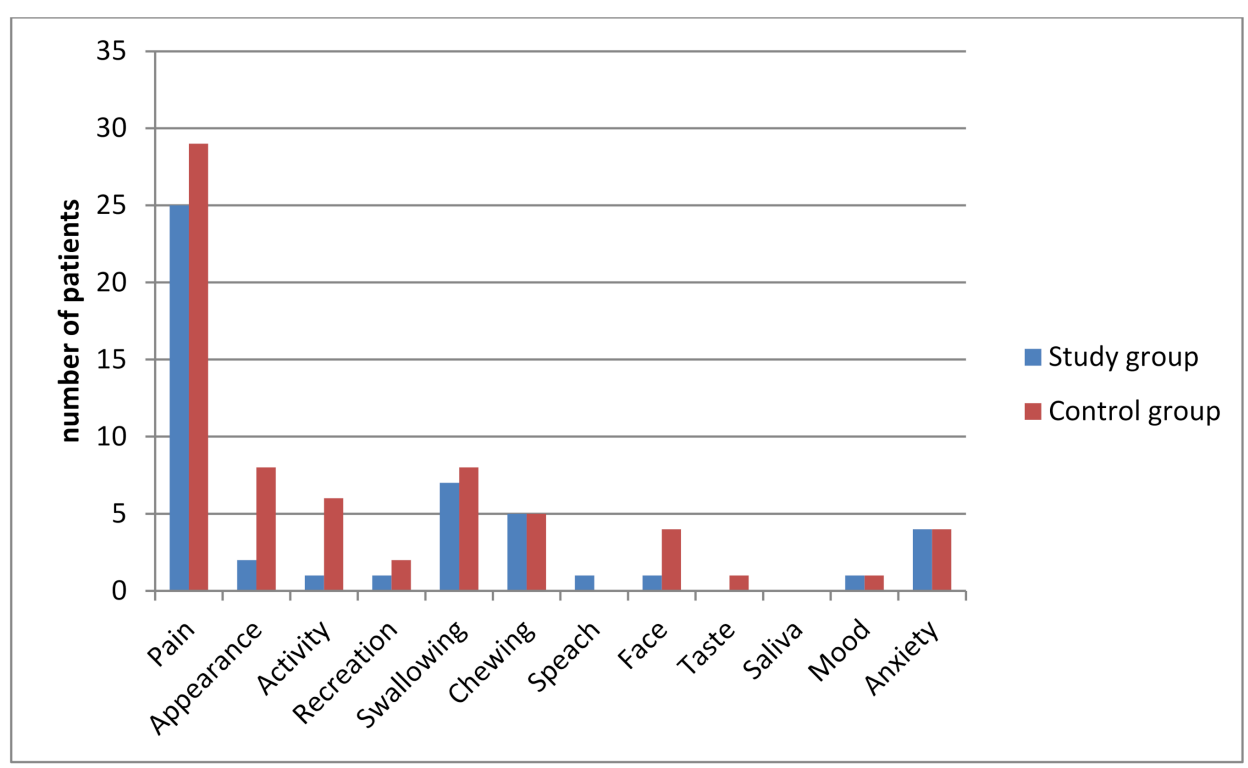

Figure 3. Significant problems for patients during recovery after removal of ITM.

\section{Discussion}

The concept of postoperative quality of life determines the impact of surgical procedures on the change in everyday functioning activity and the degree of postoperative pain. Previous studies have demonstrated a decrease in the QoL after third molar surgery as well as after routine teeth extractions [22,23]. However, to the best of our knowledge, there were no studies which implemented University of Washington Quality of Life Questionnaire (UW-QoLv4) for QoL assessment. The typically employed questionnaires include the 14-item Oral Health Impact Profile (OHIP-14), the 16-item UK Oral Health-related Quality of Life measure (OHIP-16) (The Oral Health Impact Profile-16), OHQOLUK-16 (United Kingdom Oral Health-related Quality of Life measure questionnaire -16), EQ 5D-3L (The EuroQol Group questionnaire-5 Dimensions and 3 Levels), OHRQoLUK (United Kingdom Oral Health-related Quality of Life instrument), and PoSSe (Postoperative Symptom Severity questionnaire) [7,10,22-28]. EQ 5D-3L studies showed improvement in postoperative QoL after seven days but with a significant decrease immediately after the surgery [6]. This questionnaire does not inquire about health before operation; thus, no comparison with the preoperative period is possible. By contrast, in our study, the QoL questionnaire was employed also before treatment, and that allowed for comparison of health status before and after the surgery.

Moreover, the questionnaire we use is reliable, valid, sensitive and precise [18]. Validity of the questionnaire is confirmed by the substantial number of publications that use UW-QoL v4. We decided to use UW-QoLv4 because it is validated, simple to process, and proven to provide clinically relevant information about the patient's physical and mental condition $[29,30]$.

According to Deepti, QoL decreases within a 5-day postoperative period [7]. However, between the 6 th and 7 th postoperative days, the decrease was found to not be statistically important. In the present study, application of Kinesio Tape lasted 5 days and it was assumed that 7 days are required to return to the proper daily activity.

According to the results of the present study, two domains were not important problems in both groups since the most important issues and problems were: "pain", "appearance" and "activity". In the study by Raymond involving 630 patients, the surgery affected the QoL of approximately half of the patients and the most important issue for them was compromised oral function and pain. In the current series, apart from "pain", "swallowing" and "chewing" were also the most important issues for patients of both groups. Likewise, McGrath noticed a significant decrease in QoL after third molar surgery in the immediate postoperative period [31]. In turn, Grossi revealed that the most affected domains were 
"eating" and "interference with daily activities" [32]. In addition, in Braimah's study, the significantly affected domains were "eating", "laughing", "smiling", "work", and "speech" [33]. The difference between the results of studies for specific domains may be the cause of various populations appraised. The geographical aspect should be taken into consideration and its relationship to important issues chosen by patients.

In the studies of Ristow et al. [15,34-36] on the impact of surgical removal of the impacted mandibular third molar, surgical treatment of the zygomatic-orbital and mandibular fractures on patients' quality of life, the assessment was made by asking four questions to the patients of the study group and two questions to the control group. The questions concerned the patient's satisfaction after the procedure and the evaluation of facial swelling. In the group with the applied KT, the patients were asked if the KT disturbed their daily functioning and if their presence inhibited the possibility of head movement. It was, therefore, less extensive than the questionnaire used in the self-examination, which consisted of more questions and was used in the same form both in the examined and control group.

Yurttutan et al. [37] compared different treatments for patients with mandibular third molars and mild pericoronitis. Treatment by extraction or by a periodontal approach and its effect on QoL were compared. Tooth extraction, long term, was more effective than periodontal treatment. Unfortunately, the effect of KT tide on QoL was not assessed.

Ibikunle demonstrated that injection of prednisolone or cryotherapy after third molar surgery resulted in a lesser decrease in QoL in comparison with the control group. The domains "ability to chew", "ability to swallow" and "diet change" were most often reported as affected and the scores were significantly higher in patients without prednisolone injection $[27,29]$. Likewise, dexamethasone injections used in the study by Deo caused lower deterioration of QoL as compared to the control group. Although changes in the domains "speech", "eating", "sickness" and "interference with daily activity" were recorded, significant differences were demonstrated only in domain "sickness" [38].

Similarly, LLLT has an impact on pain intensity and swelling problems after third molar surgery. In a study by Bantinjan, where no questionnaire was used, patients subjected to the laser therapy indicated their symptoms as less nagging then in the control group [39]. The study by Colorado-Bonnin et al. showed that over $50 \%$ of participants had to withdraw from their work for the period of convalescence, and as the main reason for the decrease in their QOL, they indicated pain and edema, which led to their social isolation. Over $40 \%$ of patients did not maintain their standard activity. Patients often also refrained from practicing sports and other hobbies (68.1\%) [8]. Likewise, in the present study "activity" and "mood" on the 7th day were significantly higher in patients with KT than in the control group as well as the difference between questionnaire filled on the seventh day and pre-operative period in "Overall QoL during the past 7 days" and "activity".

Although the results of the study are promising, KT improves postoperative QoL compared to the no KT application, the study has some limitations. Although the study group was not very numerous (100 people), according to the authors' knowledge it was the largest of the reported studies so far. In addition, the study could be extended by determining the degree of retention of the mandibular third molar, as well as classification of the position of the impacted tooth in relation to IAN. It is difficult to obtain a blinded control and study group due to the fact that KT tapes are applied to the patient's skin and are visible.

The QoL assessment questionnaire included a question of appearance. However, it was only determined on the basis of the patient's subjective evaluation. Volumetric measurements using extraoral 3D scanners and a comparison of color maps of the obtained triangle mesh in the form of an stl file can minimize the risk of measurement inaccuracies and errors. Therefore, the next step in our research will be the measurement of this variable by means of a three-dimensional analysis of the obtained triangle mesh in the face scanning process and reference of the results to postoperative QoL [40-42]. 
In addition, the study of the quality of life of patients after surgical removal of a detained third molar in the mandible is a subjective study. The results represent only the subjective feelings of the patient [43]. QoL questionnaires are a tool to standardize results.

In our study, the removal of impacted mandibular third molar was performed unilaterally. The examination of two types of therapies in one patient makes it possible to compare their therapeutic effect. Each patient feels the intensity of the pain differently, so a split-mouth study would provide the best results [44]. However, it should be kept in mind that in split-mouth tests, the removal of teeth on the right and left side cannot be conducted at the same time, as this will affect the patient's subjective feelings.

\section{Conclusions}

Proper postoperative care, reduction in postoperative pain and monitoring of the decrease in quality of life have become one of the main goals of modern dental surgery. Therefore, it is important to seek for non-invasive methods to reduce the level of postoperative non-infectious complications. The use of KT has a significant impact on improving the quality of life of patients after surgical extraction of the lower wisdom tooth in the following areas: "Overall quality of life", "Quality of health in the last seven days", "Mood" and "Activity". The use of KT significantly affects the quality of life of patients, between the day of surgical extraction of the lower wisdom tooth and the seventh postoperative day, in the following areas: "Overall quality of life" and "Activity". Patients with Kinesio Tape had better QoL than in the control group and its application did not disturb their daily activities. The presented results suggest that Kinesio Taping allows improvement in QoL after third molar removal.

Author Contributions: Conceptualization, G.T. and O.P.; methodology, O.P. and G.T.; software, A.J. and B.K.; validation, G.T. and A.J.; formal analysis, O.P. and A.J.; investigation, O.P. and G.T.; resources, O.P., A.J. and B.K.; data curation, A.J. and O.P.; writing—original draft preparation, O.P. and A.J.; writing - review and editing, G.T. and A.J.; visualization, O.P., A.J. and B.K.; supervision, G.T.; project administration, G.T.; All authors have read and agreed to the published version of the manuscript.

Funding: This research received no external funding.

Institutional Review Board Statement: The study was conducted according to the guidelines of the Declaration of Helsinki, and approved by the Institutional Ethics Committee of Pomeranian Medical University in Szczecin, Poland (KB-0012/152/13-KB-0012/135/15).

Informed Consent Statement: Informed consent was obtained from all subjects involved in the study.

Data Availability Statement: The data presented in this study are available on request from the corresponding author.

Conflicts of Interest: The authors declare no conflict of interest.

\section{References}

1. Bui, C.H.I.; Seldin, E.; Dodson, T. Types, frequencies, and risk factors for complications after third molar extraction. J. Oral Maxillofac. Surg. 2003, 61, 1379-1389. [CrossRef] [PubMed]

2. Yuasa, H.; Sugiura, M. Clinical postoperative findings after removal of impacted mandibular third molars: Prediction of postoperative facial swelling and pain based on preoperative variables. J. Oral Maxillofac. Surg. 2004, 42, 209-214. [CrossRef]

3. Zandi, M.; Amini, P.; Keshavarz, A. Effectiveness of cold therapy in reducing pain, trismus, and edema after impacted mandibular third molar surgery: A randomized, self-controlled, observer-blind, split-mouth clinical trial. Int. J. Oral Maxillofac. Surg. 2016, 45, 118-123. [CrossRef]

4. Osunde, O.; Saheeb, B.; Bassey, G. Indications and risk factors for complications of lower third molar surgery in a nigerian teaching hospital. Ann. Med. Health Sci. Res. 2014, 4, 938-942. [CrossRef] [PubMed]

5. Duarte-Rodrigues, L.; Miranda, E.F.P.; Souza, T.O.; de Paiva, H.N.; Falci, S.G.M.; Galvão, E.L. Third molar removal and its impact on quality of life: Systematic review and meta-analysis. Qual. Life Res. 2018, 27, 2477-2489. [CrossRef]

6. Beech, A.N.; Haworth, S.; Knepil, G.J. Measurement of generic compared with disease-specificquality of life after removal of mandibular third molars: A patient-centered evaluation. Br. J. Oral Maxillofac. Surg. 2017, 55, 274-280. [CrossRef] 
7. Deepti, C.; Rehan, H.S.; Mehra, P. Changes in quality of life after surgical removal of impacted mandibular third molar teeth. J. Oral Maxillofac. Surg. 2009, 8, 257-260. [CrossRef]

8. Colorado-Bonnin, M.; Valmaseda-Castellon, E.; Berini-Aytes, L.; Gay-Escoda, C. Quality of life following lower third molar removal. Int. J. Oral Maxillofac. Surg. 2006, 35, 343-347. [CrossRef]

9. Beech, A.N.; Haworth, S.; Knepil, G.J. Effect of a domiciliary facial cooling system on generic quality of life after removal of mandibular third molars. Br. J. Oral Maxillofac. Surg. 2018, 56, 315-321. [CrossRef]

10. Shugars, D.A.; Gentile, M.A.; Ahmad, N.; Stavropoulos, M.F.; Slade, G.D.; Phillips, C.; Conrad, S.M.; Fleuchaus, P.T.; White, R.P., Jr. Assessment of oral health-related quality of life before and after third molar surgery. J. Oral Maxillofac. Surg. 2006, 64, 1721-1730. [CrossRef]

11. Chugh, A.; Singh, S.; Mittal, Y.; Chugh, V. Submucosal injection of dexamethasone and metyloprednisolone for the control of postoperative sequelae after third molar surgery: Randomized controlled trial. Int. J. Oral Maxillofac. Surg. 2018, 47, 228-233. [CrossRef]

12. Kocer, G.; Yuce, E.; Tuzuner, O.A.; Dereci, O.; Koskan, O. Effect of the route of administration of methylprednisolone on oedema and trismus in impacted lower third molar surgery. Int. J. Oral Maxillofac. Surg. 2014, 43, 639-643. [CrossRef]

13. Aras, M.H.; Güngörmüs, M. Placebo-controlled randomized clinical trial of the effect two different low-level laser therapies (LLLT) - intraoral and extraoral—on trismus and facial swelling following surgical extraction of the lower third molar. Lasers Med. Sci. 2010, 25, 641-645. [CrossRef]

14. Filho, J.R.L.; Silva, E.D.; Camargo, I.B.; Gouveia, F.M.V. The influence of cryotherapy on reduction of swelling, pain and trismus after third molar extraction. J. Am. Dent. Assoc. 2005, 136, 774-778. [CrossRef] [PubMed]

15. Ristow, O.; Pautke, C.; Kehl, V.; Koerdt, S.; Hahnefeld, L.; Hohlweg-Majert, B. Kinesiologic taping reduces morbidity after oral and maxillofacial surgery: A pooled analysis. Physiother. Theory Pract. 2014, 30, 390-398. [CrossRef] [PubMed]

16. Jaroń, A.; Jedliński, M.; Grzywacz, E.; Mazur, M.; Trybek, G. Kinesiology Taping as an Innovative Measure against Post-Operative Complications after Third Molar Extraction-Systematic Review. J. Clin. Med. 2020, 9, 3988. [CrossRef]

17. Jaron, A.; Preuss, O.; Grzywacz, E.; Trybek, G. The Impact of Using Kinesio Tape on Non-Infectious Complications after Impacted Mandibular Third Molar Surgery. Int. J. Environ. Res. Public Health 2021, 18, 399. [CrossRef]

18. Kase, K.; Wallis, J.; Kase, T. Clinical Therapeutic Applications of the Kinesio Taping Method, 2nd ed.; Ken Ikai: Tokyo, Japan, 2003.

19. Gómez-Soriano, J.; Abián-Vicén, J.; Aparicio-García, C.; Ruiz-Lázaro, P.; Simón-Martínez, C.; Bravo-Esteban, E.; FernándezRodríguez, J.M. The effects of Kinesio taping on muscle tone in healthy subjects: A double-blind, placebo-controlled crossover trial. Mannual Ther. 2014, 19, 131-136. [CrossRef]

20. Lowe, D.; Rogers, S.N. Guidance for Scoring and Presentation: University of Washington Quality of Life Questionnaire (UWQOL v4). 2012. Available online: http://www.hancsupport.com/sites/default/files/assets/pages/UW-QOL-update_2012.pdf (accessed on 12 September 2020).

21. Shieh, G.; Jan, S.L.; Randles, R.H. On power and sample size determinations for the Wilcoxon-Mann-Whitney test. J. Nonparametric Stat. 2006, 18, 33-43. [CrossRef]

22. Adeyemo, W.L.; Taiwo, O.A.; Oderinu, O.H.; Adeyemi, M.F.; Ladeinde, A.L.; Ogunlewe, M.O. Oral health-related quality of life following non-surgical (routine) tooth extraction: A pilot study. Contemp. Clin. Dent. 2012, 3, 427-432. [CrossRef]

23. Bradshaw, S.; Faulk, J.; Blakey, G.H.; Phillips, C.; Phero, J.A.; White, R.P., Jr. Quality of life outcomes after third molar removal in subjects with minor symptoms of pericoronitis. J. Oral Maxillofac. Surg. 2012, 70, 2494-2500. [CrossRef] [PubMed]

24. Kieffer, J.M.; van Wijk, A.J.; Ho, J.P.; Lindeboom, J.A. The internal responsiveness of the Oral Health Impact Profile-14 to detect differences in clinical parameters related to surgical third molar removal. Qual. Life Res. 2012, 21, 1241-1247. [CrossRef] [PubMed]

25. Kazancioglu, H.O.; Kurklu, E.; Ezirganli, S. Effects of ozone therapy on pain, swelling, and trismus following third molar surgery. Int. J. Oral Maxillofac. Surg. 2014, 43, 644-648. [CrossRef] [PubMed]

26. Kazancioglu, H.O.; Ezirganli, S.; Demirtas, N. Comparison of the influence of ozone and laser therapies on pain, swelling, and trismus following impacted third-molar surgery. Lasers Med. Sci. 2013, 29, 1313-1319. [CrossRef]

27. Ibikunle, A.A.; Adeyemo, W.L.; Ladeinde, A.L. Oral health-related quality of life following third molar surgery with either oral administration or submucosal injection of prednisolone. J. Oral Maxillofac. Surg. 2016, 20, 343-352. [CrossRef]

28. Ibikunle, A.A.; Adeyemo, W.L. Oral health-related quality of life following third molar surgery with or without application of ice pack therapy. J. Oral Maxillofac. Surg. 2016, 20, 239-247. [CrossRef]

29. Hassan, S.J.; Weymuller, E.A., Jr. Assessment of quality of life in head and neck cancer patients. Head Neck 1993, 15, 485-496. [CrossRef]

30. Weymuller, E.A., Jr.; Alsarraf, R.; Yueh, B.; Deleyiannis, F.W.; Coltrera, M.D. Analysis of the performance characteristics of the University of Washington Quality of Life instrument and its modification (UW-QOL-R). Arch. Otolaryngol. Head Neck Surg. 2001, 127, 489-493. [CrossRef]

31. McGrath, C.; Comfort, M.B.; Lo, E.C.; Luo, Y. Changes in life quality following third molar surgery-the immediate postoperative period. Br. Dent. J. 2003, 194, 265-268. [CrossRef]

32. Grossi, G.B.; Maiorana, C.; Garramone, R.A.; Borgonovo, A.; Creminelli, L.; Santoro, F. Assessing Postoperative Discomfort After Third Molar Surgery: A Prospective Study. J. Oral Maxillofac. Surg. 2007, 65, 901-917. [CrossRef]

33. Braimah, R.O.; Ndukwe, K.C.; Owotade, F.J.; Aregbesola, S.B. Oral health-related quality of life (OHRQoL) following third molar surgery in Sub-Saharan Africans: An observational study. Afr. Med. J. 2016, 19, 1-6. [CrossRef] [PubMed] 
34. Ristow, O.; Hohlweg-Majert, B.; Kehl, V.; Koerdt, S.; Hahnefeld, L.; Pautke, C. Does elastic therapeutic tape reduce postoperative pain and trismus after open reduction and internal fixation of mandibular fractures. J. Oral Maxillofac. Surg. 2013, 71, 1387-1396. [CrossRef]

35. Ristow, O.; Hohlweg-Majert, B.; Sturzembaum, S.R.; Kehl, V.; Koerdt, S.; Hahnefeld, L.; Pautke, C. Therapeutic elastic tape reduces morbidity after wisdom teeth removal-a clinical trial. Clin. Oral Investig. 2014, 18, 1205-1212. [CrossRef]

36. Ristow, O.; Pautke, C.; Kehl, V.; Koerdt, S.; Schwarzler, K.; Hahnefeld, L.; Hohlweg-Majert, B. Influence of kinesiologic tape on postoperative swelling, pain and trismus after zygomatico-orbital fractures. J. Craniomaxillofac. Surg. 2014, 42, 469-476. [CrossRef]

37. Yurttutan, M.E.; Karaahmetoğlu, Ö.; Üçok, C.; Bağış, N. Comparison of the quality of life of patients with mandibular third molars and mild pericoronitis treated by extraction or by a periodontal approach. Br. J. Oral Maxillofac. Surg. 2020, 58, 179-184. [CrossRef]

38. Deo, S.P. Single-Dose of Submucosal Injection of Dexamethasone Affects the Post Operative Quality of Life After Third Molar Surgery. J. Oral Maxillofac. Surg. 2016, 15, 367-375. [CrossRef]

39. Batinjan, G.; Filipović, Z.I.; Rupić, I.; Bag, J.I.; Zore, Z.; Gabrić, P.D. Assessing Health-Related Quality of Life with Antimicrobial Photodynamic Therapy (APDT) and Low Level Laser Therapy (LLLT) after Third Molar Removal. J. Lasers Med. Sci. 2013, 4, 120-126.

40. Kau, C.H.; Cronin, A.; Durning, P.; Zhurov, A.I.; Sandham, A.; Richmond, S. A new method for the 3D measurement of postoperative swelling following orthognathic surgery. Orthod Craniofac. Res. 2006, 9, 31-37. [CrossRef] [PubMed]

41. Yip, E.; Smith, A.; Yoshino, M. Volumetric evaluation of facial swelling utilizing a 3-D range camera. Int. J. Oral Maxillofac. Surg. 2004, 33, 179-182. [CrossRef]

42. Metlerski, M.; Grocholewicz, K.; Jaron, A.; Lipski, M.; Trybek, G. Comparison of Presurgical Dental Models Manufactured with Two Different Three-Dimensional Printing Techniques. J. Health Eng. 2020, 29, 3338. [CrossRef]

43. Tatli, U.; Benlidayi, I.C.; Salimov, F.; Guzel, R. Effectiveness of kinesio taping onpostoperative morbidity after impacted mandibular third molar surgery: A prospective, randomized, placebo-controlled clinical study. J. Appl. Oral Sci. 2020, 28, e20200159. [CrossRef] [PubMed]

44. Younger, J.; McCue, R.; Mackey, S. Pain outcomes: A brief review of instruments and techniques. Curr. Pain Headache Rep. 2009, 13, 39-43. [CrossRef] [PubMed] 